\title{
ESTÁGIO CURRICULAR: UM ESTUDO NO CURSO DE GRADUAÇÃO EM ADMINISTRAÇÃO EM UMA INSTITUIÇÃO DE ENSINO SUPERIOR NO RECÔNCAVO DA BAHIA
}

\author{
CURRICULAR INTERNSHIP: A STUDY IN AN ADMINISTRATION COURSE OF A HIGHER \\ EDUCATION INSTITUTION IN THE RECÔNCAVO DA BAHIA
}

Milena Fonseca Machado ${ }^{1}$

Andrea de Oliveria Silva ${ }^{2}$ Ana Virginia Pereira dos Santos

\begin{abstract}
O estágio é legalmente um componente relevante para os estudantes que cursam o nível superior, é a oportunidade do graduando pôr em prática todo o conhecimento teórico adquirido na sua trajetória acadêmica, pois nesse momento o aluno poderá desenvolver habilidades e competências essências para o administrador, possibilitando ao estudante uma maior preparação para entrar no mercado de trabalho. A prática do programa de estágio previsto pela matriz curricular do curso deve respeitar a Lei 11.788/08. Esta lei trás novas normas que buscam oportunizar a melhor experiência ao graduando, com todos os deveres e obrigações de ambas as partes, evitando a distorção da atividade. Dessa maneira, o objetivo geral desta pesquisa foi analisar a percepção dos graduandos acerca do estágio supervisionado no curso de Administração de uma faculdade privada do Recôncavo da Bahia. Quanto aos pressupostos metodológicos, esta pesquisa caracteriza-se como um estudo de caso, de teor descritivo. Adotou-se o questionário como instrumento de coleta de dados e técnicas qualitativas para o seu análise. Os resultados obtidos revelaram a compreensão dos estudantes nos aspectos básicos da legislação do estágio, a identificação de ações de acompanhamento da instituição de ensino, a presença do professor orientador, a falta de compatibilidade das teorias com a prática e a contribuição do estágio para a formação profissional. Além disso, foi percebida a valorização do estágio, assim como o comprometimento da instituição de ensino nos acompanhamentos realizados sobre as atividades desenvolvidas por esses estagiários. Enquanto desafios enfrentados, destaca-se a dificuldade de conciliar o tempo entre o trabalho e a inflexibilidade das organizações.
\end{abstract}

Palavras-chave: Mercado. Aprendizagem. Estágio.

The internship is a legally relevant component for university students, because it is their opportunity to apply the theoretical knowledge acquired during their academic life and develop essential skills and competences to enter the market. The internship program foreseen in the curriculum must comply with the institutionalized Law 11.788/08. This law introduces new norms, seeking to provide the best experience for graduates with all the duties and obligations of both parties in order to reduce distortions. The general objective of this research was to analyze the students' perceptions about the supervised compulsory internship in an Administration course of a private university located in the Recôncavo da Bahia, Brazil. As for the methodological assumptions, this research is characterized as a descriptive case study within a qualitative approach. Data were collected by means of a questionnaire. The results obtained revealed the students' understanding of the basic aspects of the internship legislation, the identification of follow-up actions of the teaching institution, the presence of the tutor, the compatibility of the theory in practice and the contribution of the internship to the professional training. In addition, students recognized the importance of the internship as well as the commitment of the institution in the follow-up of the activities carried out by these trainees. According to the students, the most difficult challenges faced were the lack of time and the inflexibility of the organizations

Keywords: Job Market. Internship. Learning

Recebido: 27/02/2019

Aceito: $11 / 06 / 2019$

${ }^{1}$ Graduada em Administração pela Faculdade Maria Milza E-mail: milena.machado89@gmail.com

${ }^{2}$ Graduada em Administração pela ENEB, Especialista em Gestão de Pessoas Faculdade Visconde de Cairu, Mestre em Desenvolvimento Regional e Meio Ambiente (FAMAM), Professora do curso de Administração da FAMAM e no Centro de Integração Empresa Escola, Lattes https://wwws.cnpq.br/cvlattesweb/PKG_MENU.menu?f_cod=22533FE768F32F52B765E38D448AAB8-E-mail: andreaosilva@yahoo.com.br.

${ }^{3}$ Graduada em Economia pela Faculdade de Tecnologia e Ciências (FTC), Especialista em Metodologia da Pesquisa Científica pela

Faculdade Maria Milza (FAMAM). Mestre em Planejamento do Desenvolvimento, pela Universidade Federal do Pará (UFPA). Professora na

FAMAM. Lattes http://lattes.cnpq.br/1018284919932966Email anavps_@hotmail.com. 


\section{INTRODUÇÃO}

O estágio é considerado legalmente um componente relevante para os estudantes de nível superior. Na verdade, é a oportunidade do graduando utilizar todo o conhecimento teórico adquirido na sua trajetória acadêmica.Nesse momento, o estudante poderá desenvolver habilidades e competências essenciais para o futuro profissional, que possibilitam uma maior preparação para entrar no mercado de trabalho.

A prática do programa de estágio previsto pela grade curricular do curso deve respeitar a Lei 11.788, atualizada em 2008. Esta nova lei trás normas que buscam oportunizar a melhor experiência ao graduando e estabelece todos os deveres e obrigações de ambas as partes, evitando a distorção da atividade.

A nova legislação trás duas modalidades de estágio: obrigatório ou não obrigatório, conforme determinação das diretrizes curriculares da etapa, da modalidade e área de ensino, e do projeto pedagógico do curso. Estágio obrigatório é aquele definido como tal no projeto do curso, com uma carga horária que deve ser cumprida para aprovação e obtenção de diploma. Estágio não obrigatório é aquele desenvolvido como atividade opcional, acrescida à carga horária regular e obrigatória (BRASIL, 2008).

Nesse contexto, as organizações buscam profissionais com perfil multifuncional, capazes de contribuir na aprendizagem organizacional e, consequentemente, no alcance dos resultados. O estágio pode proporcionar ao estudante uma visão sistêmica de diferentes áreas de atuação do administrador, possibilitando, assim, aprendizado na área de interesse ou uma chance de descobrir outras áreas de atuação dentro da sua formação profissional.

Diante de um cenário onde as organizações precisam ser dinâmicas para responder às mudanças constantes, as experiências dos estágios são relevantes no aprendizado dos graduandos.O estágio pode ser considerado uma fonte de experiência que permite familiarização com as atividades empresariais, que as vezes podem ser desvirtuadas pelas empresas concedentes, caso não cumpram as claúsulas do contrato.

Assim, independentemente da obrigatoriedade do estágio, ele pode ser visto como uma ferramenta de aprendizado capaz de articular a teoria e a prática, permitindo trocas entre os conhecimentos adquiridos na graduação e as experiências vividas no ambiente organizacional. O estágio também proporciona maior entendimento e assimilação dos conteúdos teóricos ministrados nas instituições de ensino, a possibilidade de efetivação do estagiário e maior qualidade no perfil do estudante para atuar no mercado de trabalho.

Nesse sentido, para compreender a relevância do estágio na formação acadêmica e profissional do estudante, este trabalho teve como objetivo descrever e analisar qual a percepção dos graduandos acerca do estágio supervisionado obrigatório numa instituição de ensino superior (IES) privada em um curso de Administração, no Recôncavo da Bahia.

\section{METODOLOGIA}

Trata-se de uma pesquisa descritiva com abordagem qualitativa, delineada como estudo de caso, que responde a questões particulares sobre a percepção dos graduandos acerca do estágio supervisionado.

O lócus da pesquisa foi uma IES privada, localizada no Recôncavo da Bahia, que atua no mercado educacional há mais de quinze anos.

Para a coleta dos dados aplicaram-se questionários aos estudantes do $7^{\circ}$ e $8^{\circ}$ semestre do curso de Administração, devidamente matriculados na disciplina Estágio Supervisionado Obrigatório, totalizando 35 estudantes. Em virtude de 03 graduandos se negarem a participar da pesquisa, a amostra totalizou 32 estudantes. 
Durante a coleta de dados foram levantadas informações sobre aspectos da legislação do estágio, o conhecimentos dos estudantes sobre a Lei 11.788, o acompanhamento da instituição de ensino, assim como os desafios enfrentados pelos estudantes durante o estágio.

\title{
LEGISLAÇÃO DE ESTÁGIO
}

Para Barros, Alves e Araújo (2014), o estágio é considerado uma oportunidade para o estudante aperfeiçoar as práticas profissionais com base nas teorias desenvolvidas em sala de aula, com a orientação de um supervisor, que direciona o aluno para o desenvolvimento da sua capacidade de tomar decisões no ambiente de trabalho.

Bianchi, Alvarenga e Bianchi (2003) afirmam que se o estágio for visto como uma atividade que proporciona inúmeros benefícios para a aprendizagem, para uma melhora do ensino e para o estagiário, com certeza trará resultados positivos, e a maior beneficiada com esses resultados é a sociedade consciente dessa importância, em especial a comunidade em que esses egressos vão atuar profissionalmente.

E reafirmando a relevância do estágio, Colombo e Ballão (2014, p. 173) nos dizem que:

O estágio oferece ao educando a oportunidade de colocar em prática o conhecimento construído nas aulas teóricas, sob supervisão de um profissional da área que irá orientar e corrigir o estagiário em todas as atividades desenvolvidas, para que no momento em que estiver atuando como profissional, este possa aplicar a experiência adquirida, e assim esteja menos sujeito a possíveis falhas no cumprimento de suas contribuições (COLOMBO; BALLÃO, 2014, p. 173).

De acordo com a Lei 11.788 de 2008 , art. 10

\begin{abstract}
Estágio é ato educativo escolar supervisionado, desenvolvido no ambiente de trabalho, que visa à preparação para o trabalho produtivo de educandos que estejam frequentando o ensino regular em instituições de educação superior [...]
\end{abstract}

De acordo com essa lei, o estágio pode ser obrigatório ou não obrigatório. Estágio obrigatório é aquele definido como tal no projeto do curso, e o cumprimento da carga horária nele estabelecida é requisito para aprovação e obtenção de diploma. Estágio não obrigatório é aquele desenvolvido como atividade opcional, acrescida à carga horária regular e obrigatória (BRASIL, 2008).

Segundo Rodrigues (2013), o estágio supervisionado é uma etapa de formação profissional do graduando, não facultativa e pré-requisito para o recebimento da sua licença, devendo ocorrer pelo exercício direto na instituição de ensino ou em ambientes adequados e regulamentados para realização de atividades daquela área profissional.

O Conselho Nacional de Educação, através da Resolução n 01 de 2004, art. 7 dispõe que:

Art. $7^{\circ} \mathrm{O}$ Estágio Curricular Supervisionado é um componente curricular direcionado à consolidação dos desempenhos profissionais desejados inerentes ao perfil do formando, devendo cada instituição, por seus Colegiados Superiores Acadêmicos, aprovar o correspondente regulamento, com suas diferentes modalidades de operacionalização.

$\S 1^{\circ} \mathrm{O}$ estágio de que trata este artigo poderá ser realizado na própria instituição de ensino, mediante laboratórios que congreguem as diversas ordens práticas correspondentes aos diferentes pensamentos das Ciências daAdministração.

$\S 2^{\circ}$ As atividades de estágio poderão ser reprogramadas e reorientadas de acordo com 
os resultados teórico-práticos gradualmente revelados pelo aluno, até que os responsáveis pelo acompanhamento, supervisão e avaliação do estágio curricular possam considerá-lo concluído, resguardando, como padrão de qualidade, os domínios indispensáveis ao exercício da profissão.

$\S 3^{\circ}$ Optando a instituição por incluir no currículo do Curso de Graduação em Administração o Estágio Supervisionado de que trata este artigo, deverá emitir regulamentação própria, aprovado pelo seu Conselho Superior Acadêmico, contendo, obrigatoriamente, critérios, procedimentos e mecanismos de avaliação, observado o disposto no parágrafo precedente.

Roesch (2009) considera válida a prática profissional alcançada com o estágio, por relacionar a teoria com a prática, analisar problemas da empresa, aprofundar área de interesse, conhecer vários setores do ambiente industrial, etc. Almeida et al. (2006) asseveram que o espaço de realização de estágio permite ao estagiário uma aproximação do mundo do administrador.

\begin{abstract}
A especificidade do estágio em propiciar um contato próximo e concreto da realidade do administrador, se apresenta como uma ferramenta eficaz no aprendizado uma vez que estabelece o aproveitamento de experiências, promovendo a aquisição de conhecimento aplicado. Este fato decorre da constatação de que administradores não devem ser formados exclusivamente em sala de aula (ALMEIDA et al., p. 01, 2006).
\end{abstract}

O estágio promove a formação de profissionais multifuncionais, capazes de enfrentar as exigências do mercado de trabalho. Além disso, o estágio faz parte do projeto pedagógico do curso de Administração que, por sua vez, deverá respeitar a legislação do estágio.

Em 1977 foi aprovada uma lei específica para estágio, a Lei $n^{\circ} 6.494 / 77$ e Decreto $n^{\circ} 87.494 / 82$ e anulados em 2008, após a Lei 11.788/2008 ser sancionada, alterando exigências pontuadas pela legislação anterior. No Quadro 1 apresentamos diferenças entre as leis de 1977 e a de 2008 . .

Quadro 1. Comparativo entre a Lei n. 6.494/77 e 11.788/08 que regulamentam o estágio.

\begin{tabular}{|l|l|l|}
\hline \multicolumn{1}{|c|}{ Assunto } & \multicolumn{1}{|c|}{$\begin{array}{c}\text { Lei n. 6.494/77 e Decreto n. } \\
\mathbf{8 7 . 4 9 4 / 8 2}\end{array}$} & \multicolumn{1}{c|}{ Lei n. 11.788/08 } \\
\hline $\begin{array}{l}\text { Estágio no Projeto } \\
\text { Pedagógico do Curso. }\end{array}$ & $\begin{array}{l}\text { As IES são obrigadas a } \\
\text { incluírem o estágio como } \\
\text { matéria em sua diretriz } \\
\text { curricular. }\end{array}$ & $\begin{array}{l}\text { O estágio passou a fazer parte do projeto } \\
\text { pedagógico do curso e a integrar as diretrizes } \\
\text { curriculares dos cursos de graduação. }\end{array}$ \\
\hline Orientador de estágio. & $\begin{array}{l}\text { Fica como facultativo a } \\
\text { existência de um supervisor da } \\
\text { escola. }\end{array}$ & $\begin{array}{l}\text { A instituição de ensino indica um professor } \\
\text { orientador, e exige a entrega de relatórios das } \\
\text { atividades realizadas no final do período. }\end{array}$ \\
\hline $\begin{array}{l}\text { Supervisor da unidade } \\
\text { concedente. }\end{array}$ & $\begin{array}{l}\text { As unidades concedentes têm } \\
\text { por obrigatoriedade formalizar o } \\
\text { termo de compromisso entre as } \\
\text { partes envolvidas (aluno, IES e } \\
\text { unidade concedente). }\end{array}$ & $\begin{array}{l}\text { A parte concedente deve indicar funcionário } \\
\text { com formação ou experiência profissional na } \\
\text { área de atuação do estagiário, sendo mantido } \\
\text { o termo de compromisso entre os envolvidos. }\end{array}$ \\
\hline Jornada de atividades. & $\begin{array}{l}\text { Adequava-se a carga horária da } \\
\text { empresa. }\end{array}$ & $\begin{array}{l}\text { Máximo de 4 horas diárias e 20 semanais, no } \\
\text { caso de estudantes de educação especial, e } \\
\text { de seis horas diárias e 30 horas semanais, no } \\
\text { caso de estudantes do ensino superior, da } \\
\text { educação profissional de nível médio e do } \\
\text { ensino médio regular. }\end{array}$ \\
\hline
\end{tabular}




\begin{tabular}{|l|l|l|}
\hline Recesso remunerado. & $\begin{array}{l}\text { As férias eram vinculadas ao } \\
\text { calendário da empresa. }\end{array}$ & $\begin{array}{l}\text { A lei prevê ao estagiário um gozo de 30 dias } \\
\text { de recesso, que seja preferencialmente } \\
\text { durante as férias escolares, caso o estágio } \\
\text { tenha duração de um ano ou mais, não } \\
\text { excedendo o período máximo de dois anos. }\end{array}$ \\
\hline $\begin{array}{l}\text { Redução de carga } \\
\text { horária para estudos. }\end{array}$ & Não previa. & $\begin{array}{l}\text { A instituição de ensino deve comunicar a parte } \\
\text { concedente as datas das avaliações escolares } \\
\text { ou acadêmicas, para que a carga horária seja } \\
\text { reduzida nesse período, garantindo o } \\
\text { desempenho dos estudantes. }\end{array}$ \\
\hline Auxílio transporte. & Não previa. & $\begin{array}{l}\text { Oestagiário poderá receber bolsa ou outra } \\
\text { forma de contraprestação que venha a ser } \\
\text { acordada, sendo compulsória a sua } \\
\text { concessão. O auxilio transporte deve ser } \\
\text { disponibilizado pela concedente ou a mesma } \\
\text { deve disponibilizar transporte próprio. }\end{array}$ \\
\hline $\begin{array}{l}\text { Segurança do } \\
\text { trabalho. }\end{array}$ & Não previa. & $\begin{array}{l}\text { Fica como obrigação da empresa concedente } \\
\text { contratar em favor do estagiário seguro contra } \\
\text { acidentes pessoais. }\end{array}$ \\
\hline $\begin{array}{l}\text { Avaliação das } \\
\text { instalações da } \\
\text { unidade concedente. }\end{array}$ & Não previa. & $\begin{array}{l}\text { Fica como obrigação da instituição de ensino } \\
\text { fazer uma avaliação das instalações da parte } \\
\text { concedente do estágio. }\end{array}$ \\
\hline $\begin{array}{l}\text { Celebração de } \\
\text { convênios. }\end{array}$ & Era obrigatório. & \begin{tabular}{l} 
Passa a ser facultativo. \\
\hline Profissional liberal.
\end{tabular} \\
\hline Não previa. & $\begin{array}{l}\text { Os profissionais liberais de nível superior que } \\
\text { estejam devidamente registrados em seus } \\
\text { conselhos de fiscalização podem contratar um } \\
\text { estagiário. }\end{array}$ \\
\hline
\end{tabular}

Fonte: Adaptado de Souza, Amorim e Silva (2011).

A Lei 11.788/08, mais completa, apresenta o recesso remunerado antes inexistente, carga horária máxima estabelecida para o estágio, e outros fatores tornando obrigatória a contratação de seguro contra acidentes para os estudantes. Quanto às partes que podem conceder o estágio, a lei em seu art. 90 inclue pessoas jurídicas do direito privado e órgãos públicos de qualquer uma de suas instâncias, como também os profissionais liberais de nível superior que estejam devidamente registrados em seus conselhos de fiscalização.

De acordo com os art. 10 e 40 da Lei $n^{\circ} 11.788 / 2008$, podem ser estagiários os estudantes que estejam devidamente matriculados em ensino regular, nas instituições de ensino superior, de educação profissional, de ensino médio e da educação especial, como também estudantes estrangeiros que estejam regularmente matriculados em cursos superiores no Brasil.

$\mathrm{O}$ art. 50 da Lei $n^{\circ} 11.788 / 2008$ dispõe que a escolha da instituição de ensino e das empresas concedentes de estágio podem optar por um agente integrador; neste sentido tem-se o $\mathrm{CIEE}^{3}$ que vem atuando no Brasil há 50 anos como agente integrador entre empresa e escola.

Quanto ao papel desses agentes de integração, a lei dispõe, em seu art. 50, que eles atuem como auxiliares no processo de melhoramento do estágio, buscando identificar as oportunidades, ajustando suas condições de realização e tendo acompanhamento administrativo. Eles também encaminham a negociação para contratação de seguros contra acidentes pessoais, fazem o cadastro dos estudantes, selecionam os locais de estágio e organizam o cadastro das concedentes.

Como obrigações da instituição de ensino, é previsto no art. 70 da Lei $n^{\circ}$ 11.788/2008 celebrar termo de compromisso com o educando e com a parte concedente, avaliar as instalações da parte

${ }^{3} \mathrm{CIEE}$ (Centro de Integração Empresa-Escola). É uma instituição filantrópica, financiada pelo empresariado nacional, que presta assistência social e atua há mais de 50 anos, no intuito de direcionar estudantes de nível médio, superior e técnico para estágios que os ajudem a por em prática tudo que foi aprendido na teoria (CIEE, 2017). 
concedente do estágio, indicar um professor orientador, exigir do educando a apresentação periódica de relatório das atividades exercidas, zelar pelo cumprimento do termo de compromisso, elaborar normas complementares e instrumentos de avaliação dos estágios de seus educandos e comunicar à parte concedente as datas das avaliações escolares ou acadêmicas.

No que se refere às obrigações da parte concedente de estágio, é previsto, no art. 90 da Lei $n^{\circ}$ 11.788/2008, celebrar termo de compromisso com a instituição de ensino e o educando, ofertar instalações adequadas, indicar um funcionário formado ou com experiência na área de atuação do estagiário, contratar em favor do estagiário seguro contra acidentes pessoais, no desligamento do estagiário entregar termo de realização do estágio com resumo das atividades desenvolvidas por ele, manter à disposição da fiscalização toda a documentação do estágio e enviar à instituição de ensino um relatório de atividades desenvolvidas pelo educando.

O capítulo quatro da Lei $n^{\circ} 11.788$ trás informações relevantes ao estudante, tais como a jornada de estágio, que deve constar no termo de compromisso, a carga horária do estágio, podendo ser de 4 horas diárias e 20 semanais, no caso de estudantes de educação especial e dos anos finais do ensino fundamental, ou 6 horas diárias e 30 semanais, no caso de estudantes do ensino superior, da educação profissional de nível médio e do ensino médio regular.

Segundo a lei, a carga horária pode ser de 40 horas semanais de forma excepcional, quando o estágio é relativo a cursos que alternam teoria e prática, desde que não estejam programadas aulas presenciais, sendo que deve ser previsto no projeto pedagógico do curso. Aduração do estágio não pode exceder o período de dois anos, sendo obrigatório que após um ano o estagiário tenha 30 dias de recesso remunerado. O estágio poderá ser remunerado, desde que seja acordado no termo de compromisso, com direito também a vale transporte, no caso do estágio não obrigatório.

\section{O PAPEL DO ESTÁGIO NA FORMAÇÃO PROFISSIONAL}

Diante do que já foi exposto nas seções anteriores, pode-se constatar o mérito que o estágio tem sobre a formação profissional, inclusive na graduação. Nesse contexto, os autores Murari e Helal (2009, p. 264) afirmam que:

No nível superior, as competências profissionais podem ser trabalhadas a partir de sua aplicação nas organizações. Durante o estágio, o estudante pode expressar opiniões e produzir uma percepção crítica do processo produtivo. É uma oportunidade de ver a organização por diferentes ângulos, considerando a realidade das transformações sociais e econômicas (MURARI; HELAL, 2009, p. 264).

Entretanto, os autores asseveram que o convívio das instituições de ensino superior e as organizações deve acolher a interação ensino-aprendizagem, de modo a possibilitar uma formação tanto conceitual quanto prática. Para isso, são necessárias ações pedagógicas que busquem elevar o desempenho profissional dos graduandos como alternativa para incentivar o estágio. Por outra parte, Rocha-de-Oliveira e Piccinini (2012, p. 34) acrescentam que:

[...] apesar de estar sob a influência do mercado de trabalho, o estágio também está ligado ao sistema de formação, sendo organizado segundo as regras que o estruturam em cada instituição, bem como leis, decretos e normas (formais e informais) que regulamentam o sistema de formação.

Assim, o "estágio surge como uma ponte onde o estudante se apropria do instrumento dado pela sistematização do conhecimento científico e tecnológico e aplica no ambiente laboral, retroalimentando o sistema do autodesenvolvimento" (BARROS; ALVES; ARAÚJO, 2014, p. 187). 
A perspectiva do estágio na formação profissional do administrador é percebida a partir da vivência da realidade da organização do estudante de Administração, capaz de desenvolver as competências necessárias para um profissional da área, como bem colocam Festinalli, Canof e Bertuol (2007, p. 305)

"O estágio em administração, a partir da inserção na organização, o acadêmico tem condições para investigar a realidade interna e estabelecer as relações com a realidade externa, através do arcabouço de conhecimento trabalhado no decorrer do curso" (FESTINALLI; CANOF; BERTUOL, 2007, p. 305).

Piconez et al. (2012, p. 58) ressaltam a relevância do estágio no processo de formação profissional:

[...] os Estágios Supervisionados como uma parte importante da relação trabalho-escola, teoria-prática, e eles podem representar, em certa medida, o elo de articulação orgânica com a própria realidade.

$\mathrm{Na}$ colocação escola-trabalho, pode-se perceber a importância do Estágio Supervisionado como elemento capaz de desencadear a relação entre polos de uma mesma realidade e preparar mais convenientemente o aluno estagiário para o mundo do trabalho, desde que a escola e trabalho façam parte de uma mesma realidade social e historicamente determinada (PICONEZ et al., 2012, p. 58)

Almeida, Lagemann e Souza (2006, p. 2) também discutem a importância do estágio no desenvolvimento profissional dos estudantes:

O contato com a prática das organizações permite, portanto, a percepção do estagiário na sua futura realidade profissional, providenciando-lhe um contato prévio com aquilo com que se espera que interaja e modifique para o bem das organizações (ALMEIDA; LAGEMANN; SOUZA, 2006, p. 2)

De acordo com Festinalli, Canof e Bertuol (2007, p. 4),

A formação do profissional em Administração deve refletir a prática dos administradores nas organizações flexíveis. Formar gerentes implica estender as atividades de sala de aula até a organização onde eles atuam, causando algum impacto sobre o seu comportamento.

Mintzberg e Gosling (2003, p.37) corroboram "a sala de aula é o lugar para se afastar e refletir, enquanto a organização é o lugar para ligar o que foi aprendido à prática atual”.

O olhar para o estágio supervisionado como uma parcela de um processo de formação amplo tem o sentido de concebê-lo como componente articulador da formação, e encontra subsídios nas disciplinas que compõem o currículo do curso, as quais fundamentam o processo de formação, que é melhorado pelo período de estágio (FESTINALLI; CANOF; BERTUOL, 2007).

Ao discutir a formação profissional do administrador, Nicolini (2003) explica que no período inicial do curso são ministradas as disciplinas que dão suporte ao curso tais como Matemática e Contabilidade. A seguir, são apresentadas as disciplinas que darão ao estudante a capacidade de operar na área, como as teorias da administração e administração da produção. E posteriormente, o aluno pode escolher entre as várias disciplinas eletivas e complementares, para chegar numa formação que seja generalista ou especializada. Por fim, chega-se ao estágio supervisionado com o objetivo de conceber a aplicação dos conhecimentos que foram adquiridos pelos graduandos ao longo do curso. 


\section{RESULTADOS E DISCUSSÃO}

Nesta seção apresentaremos a análise dos dados levantados a partir dos questionários aplicados aos concluintes do curso de graduação em Administração no intuito de analisar a percepção dos graduandos acerca do estágio supervisionado obrigatório.

A maioria dos participantes (91\%) sabiam que a carga horária permitida pela legislação para o estágio é de 20 a 30 horas semanais. Esse resultado mostra o conhecimento efetivo dos estudantes sobre a carga horária determinada pela Lei 11.788/2008.

Quanto ao período máximo para realização do estágio na organização, 96\% dos entrevistados disseram que a duração máxima é de 24 meses e $4 \%$ afirmaram não ter conhecimento. De acordo com a Lei $11.788 / 2008$, a duração do estágio não pode exceder o período de dois anos em uma mesma concedente. Isso porque se exceder esse tempo, o estágio pode ser caraterizado como vínculo empregatício e passa a ser regido pela CLT. O entendimento sobre o assunto tanto para empresas, estudantes e instituições de ensino é imprescindível, para evitar descumprimento da lei por qualquer uma das partes envolvidas.

Quanto ao descanso remunerado permitido pela legislação do estágio, 78\% dos participantes afirmaram que esse direito do recesso remunerado tem duração de 30 dias, o que leva a crer que esse conhecimento veio de algum contato com a legislação de estágio, ou por experiência própria. Dezesseis porcento dos participantes afirmaram que o descanso é de 20 dias, levando a crer que esses não tiveram nenhum contato anterior com a legislação ou a prática do estágio. Segundo a Lei 11.788/2008, após um ano de contrato de estágio. o estagiário tem direito a 30 dias de descanso. $O$ não cumprimento da lei caracteriza vínculo empregatício, ou seja, o estagiário deverá ser efetivado pela parte concedente seguindo a legislação trabalhista e previdenciária.

Quanto à relevância atribuída pelos graduandos ao estágio como componente curricular, $81 \%$ dos estudantes concordam que o estágio é relevante e 19\% concordam parcialmente com a relevância do estágio. A maioria dos estudantes afirmou que a prática do estágio é uma experiência que contribui na aplicabilidade da teoria à prática. O contato com a realidade das organizações permite ao estagiário aprender e, simultaneamente, perceber como será a sua realidade profissional futura (ALMEIDA, LAGEMANN; SOUZA, 2006).

Os dados apontam que a maioria dos graduandos está mais atenta à sua formação profissional após a prática no ambiente organizacional. Observação similar foi feita por Festinalli, Canopf e Bertuol (2007), que afirmam que o acadêmico de Administração, durante o estágio, tem condições para questionar a realidade interna e determinar as relações com a realidade externa.

Ao questionar aos participantes se as práticas vivenciadas no estágio têm relação com as teorias aprendidas em sala de aula, 38\% desempenharam atividades compatíveis com o que estudaram, deixando subentendido que estão estagiando em áreas ligadas à Administração, e 59\% dos sujeitos disseram que são poucas as atividades compatíveis.

De modo geral, observa-se a predominância de graduandos que afirmaram que durante o estágio realizaram poucas atividades compatíveis com o curso, o que reforça o papel da IES no acompanhamento das atividades. De acordo com a Lei 11.788/2008, é obrigação da IES indicar um professor para acompanhar as atividades desempenhadas pelo estagiário e zelar pelo cumprimento do termo de compromisso, podendo encaminha-lo para outra empresa caso sejam descumpridas as normas.

Quanto à avaliação dos estudantes sobre o estágio supervisionado, 94\% avaliaram o estágio como uma contribuição para o aperfeiçoamento profissional, por agregar valor, conhecimento e aprendizado.

Os dados reafirmam as informações apresentadas em que os graduandos reconhecem que o estágio vai além de apenas uma atividade obrigatória para cumprimento da grade curricular. "O contato com a prática das organizações que permitirá ao estagiário a percepção da sua futura realidade profissional, promovendo-lhe um contato prévio com aquilo com que se espera que interaja e remodele 
para o bem das organizações" (ALMEIDA;LAGEMANN; SOUZASouza, 2006, p. 2).

No que se refere à percepção acerca do acompanhamento realizado pela IES durante o estágio, $47 \%$ dos estudantes disseram que a IES acompanha parcialmente e $41 \%$ deles disse que a IES acompanha regularmente essas atividades. Os dados apontam para a necessidade de intensificar as ações e a sua divulgação, já praticadas pela instituição.

Nesse sentido, o resultado confirma que a IES está cumprindo o art. 70 da Lei 11.788/2008, que determina a obrigatoriedade da instituição acompanhar as atividades desenvolvidas por seus estudantes durante o estágio supervisionado.

No que se refere ao acompanhamento do professor orientador do estágio, $59 \%$ dos graduandos questionados percebem a sua importância e 38\% realizam contato com o supervisor de estágio. Compreende-se que a instituição de ensino responsável pelos estágios supervisionados está cumprindo com a legislação, mantendo o professor orientador para atuar nos acompanhamentos nas instalações da concedente. A IES tem a obrigação de designar um professor orientador para acompanhar e avaliar as atividades desenvolvidas por esses estudantes no estágio, segundo previsto no art. 70 da Lei $n^{\circ}$ $11.788 / 2008$ conforme celebração do termo de compromisso de estágio.

O professor orientador deve exigir do estagiário a apresentação periódica de relatório das atividades exercidas e o cumprimento do termo de compromisso. Por outro lado, esse professor tem a obrigação de elaborar normas complementares e instrumentos de avaliação dos estágios de seus educandos e comunicar à parte concedente as datas das avaliações escolares ou acadêmicas (BRASIL, 2008).

Muitas são as habilidades que podem ser desenvolvidas no estágio, entre elas a capacidade de resolver problemas e a adoção de atitudes acordes com a filosofia da empresa. No entanto, as respostas coletadas indicam uma baixa percepção por parte dos estagiários dessas habilidades conceituais e humanas. Isso pode estar acontecendo devido a dois fatores possíveis: à empresa concedente não está dando os meios para que os estagiários desenvolvam essas habilidades ou o estagiário não está sabendo como desenvolvê-las.

Trabalhar com pessoas, ouvi-las, compreendê-las e motivá-las constantemente é uma das habilidades que precisa ser desenvolvida pelo futuro profissional. O administrador trabalha com pessoas e com grupos, e a habilidade conceitual proporciona valores e princípios que direcionam o comportamento e as ações futuras, além de proporcionar a capacidade de diagnosticar problemas nas organizações (CHIAVENATO, 2001).

Em relação à percepção dos estudantes sobre a melhoria na formação profissional por meio do estágio, a ampla maioria dos graduandos (94\%) concordaram que o estágio promove melhoria na formação profissional.

Percebe-se que os graduandos consideram a experiência no estágio uma forma de se firmar no mercado de trabalho. Nos tempos atuais, a formação de profissionais deve ser generalista e adaptável às diversas situações e realidade de uma organização. Na graduação, as competências profissionais podem ser exercitadas a partir da sua aplicação prática nas organizações, no período de estágio, quando o estudante pode expor suas opiniões e gerar uma percepção critica acerca do processo produtivo. Tratase de uma oportunidade para observar os diversos ângulos da organização, considerando a realidade das transformações ocorridas (MURARI; HELAL, 2009).

Quanto aos desafios enfrentados pelos participantes durante o período do estágio supervisionado, diversas situações foram relatadas, como a ausência de autonomia para desenvolver o processo decisório, atuação do estagiário apenas como observador, a falta de compatibilização das atividades praticadas com a grade curricular e a restrição para acesso a alguns setores da empresa.

Outros pontos negativos levantados neste estudo referem-se à adaptação aos sistemas da empresa, disseminação e socialização de informações dos demais colaboradores, oportunidade de ser ouvido pela empresa, simplicidade das atribuições e a falta de treinamento sobre os processos e procedimentos para o estagiário assumir o cargo.

Outros fatores considerados pelos participantes como dificuldades no estágio foram pouca 
comunicação entre supervisor e estagiário, assunção de responsabilidades em situações sem precedentes, a adaptação à cultura organizacional e o desempenho de funções relacionadas a outras áreas.

Entende-se que muitos desses desafios podem acontecer devido à inexistência de estrutura apropriada para o desenvolvimento do estagiário ou mesmo, o estudante pode ter dificuldades para se posicionar na empresa.

Cinquenta e seis por cento dos estagiários reconheceu a importância da indicação de um funcionário formado ou com experiência na área de atuação do aluno; $25 \%$ reconheceu a oferta de instalações adequadas e 19\% mencionou o envio de relatórios para a instituição de ensino . Esses dados evidenciam o quanto os graduandos estão atentos a tudo o que pode influenciar a sua formação.

Pode-se então concluir que os dados apresentados estão de acordo com o art. 90 da Lei $n^{\circ}$ $11.788 / 2008$, que explicita quais são as obrigações da parte concedente do estágio, tais como indicar um funcionário formado ou com experiência na área de atuação do estagiário e enviar à instituição de ensino um relatório de atividades desenvolvidas pelo educando.

\section{CONSIDERAÇÕES FINAIS}

A referida pesquisa permitiu esboçar uma análise sobre a percepção dos graduandos acerca do estágio supervisionado obrigatório no curso de Administração de uma IES localizada no Recôncavo da Bahia. Nesse contexto, após análise dos dados da pesquisa foi possível responder a todos os objetivos propostos.

De acordo com os dados encontrados, pode-se verificar a compreensão dos estagiários sobre a legislação do estágio. Os estudantes possuem conhecimento acerca da legislação no que diz respeito à carga horária permitida, à duração do estágio e ao período de descanso permitido. Além disso, afirmam reconhecer a relevância do estágio enquanto matéria obrigatória na grade curricular.

Entretanto, muitos estudantes que estão estagiando ainda desconhecem alguns aspectos da lei de estágio para poder zelar por uma prática adequada ao seu curso, como as obrigações por parte das concedentes e da instituição de ensino, independentemente da boa percepção sobre as ações praticadas por eles. A não distinção das práticas obrigatórias impossibilita o estagiário de identificar as ações que descumprem a lei.

Em relação às ações de acompanhamento por parte das IES nas atividades desenvolvidas pelos graduandos, foi notada a existência de ações tais como a exigência de relatórios das atividades desempenhadas e designação de um professor orientador de estágio para fazer esse acompanhamento. No entanto, foi identificado que boa parte desses estagiários está realizando atividades que pouca relação tem com as teorias aprendidas em sala de aula.

Outro fator relevante foram os desafios enfrentados pelos graduandos durante o estágio obrigatório, como ausência de autoconfiança, atuação apenas como observador, falta de compatibilização das atividades desenvolvidas com a grade curricular, restrição de acesso a alguns setores da empresa, poucas organizações acatam ou permitem sugestões de melhorias, setores bem estruturados para acolher os estagiários, organizações familiares e atividades insuficientes na prática dos estágios.

Outros fatores também foram considerados pelos participantes com dificuldades no estágio, como pouca comunicação entre supervisor e estagiário, assunção de responsabilidades em situações sem precedentes, adaptação à cultura organizacional e desempenho de funções relacionadas a outras áreas. Outra dificuldade que emerge desta pesquisa foi identificar empresas na região do Recôncavo com interesse em firmar parcerias para prover os estágios.

Em resposta aos resultados desta pesquisa, parece necessário sugerir para os estudantes melhor compreensão da legislação, atenção aos aspectos da sua formação profissional na intensão de serem 
promovidos ou perceber o estágio enquanto ferramenta para aprendizado, local de inserção no mercado de trabalho e ambiente para adquirir experiência e aperfeiçoamento profissional. Para a instituição de ensino disponibilizar melhor acompanhamento dos estágios para evitar disfunções nas atividades exigindo das empresas assim como orientações das atividades praticadas evitando disfunções de suas atribuições.

Por fim, os resultados encontrados na pesquisa a partir da percepção dos estudantes confirmam a relevância que o estágio supervisionado obrigatório tem para a formação acadêmica e profissional do administrador. Por outro lado, os graduandos reconhecem a importância dessa atividade na sua formação profissional, uma vez que permite a associação entre teoria e prática.

O presente trabalho não tem como intenção por fim às discussões acerca do estágio supervisionado obrigatório. Espera-se com esta pesquisa apenas que ambas as partes envolvidas na realização do estágio possam observar os pontos fortes e fracos e buscar a melhoria de suas práticas e programas de estágio, no intuito de torná-lo o mais eficiente possível.

\section{REFERÊNCIAS}

ALMEIDA, Denise Ribeiro de; LAGEMANN, Letícia; SOUSA, Silvio Vanderlei Araújo. A importância do estágio supervisionado para a formação do administrador. In: Encontro da Associação Nacional dos Programas de Pós-Graduação em Administração, 30., Salvador. Anais... Salvador: ANPAD, 2006. Disponível em: <www.anpad.org.br/enanpad/2006/dwn/enanpad2006-epqa-0709>. Acesso em: 23 abr. 2017.

BARROS, Bruno Henrique Lima de; ALVES, Eraldete Carneiro; ARAÚJO, Richard Medeiros de. Estágio Supervisionado em Secretariado Executivo: a visão do graduando concluinte. Revista de Gestão e Secretariado, São Paulo, v. 5, n. 2, p. 179-198, maio/agosto 2014. Disponível em: < https://www.revistagesec.org.br/secretariado/article/view/267>. Acesso em: 25 de mar. 2017.

BIANCHI, Anna Cecília de Moraes; ALVARENGA, Marina; BIANCHI, Roberto. Manual de orientação: estágio supervisionado. 3 ed. São Paulo: Pioneira Thompson Learning, 2003.

BRASIL. Lei ${ }^{\circ} 11.788$ de 25 de setembro de 2008, Brasília, DF. Presidência da República Casa Civil. Disponível em: <http://www.planalto.gov.br/ccivil_03/_ato2007-2010/2008/lei//11788.htm>. Acesso em: 09 abr. 2017.

Lei $\mathbf{n}^{\circ} 6.494$ de 7 de dezembro 1977, Brasília, DF. Presidência da República Casa Civil. Disponível em:<http://www.planalto.gov.br/ccivil_03/leis/L6494.htm>.Acesso em: 15 nov. 2017.

CNE/CSE. Resolução $n^{\circ}$ 4, de 13 de julho de 2005. Institui as Diretrizes Curriculares Nacionais do curso de Graduação em Administração, bacharelado, e dá outras providências. Brasília: Diário Oficial da União. 2005. Disponível em: < portal.mec.gov.br/cne/arquivos/pdf/rces004>. Acesso em: 27 ago. 2017.

CNE/CSE. Parecer 146/2002, de 13 de maio de 2002. Diretrizes Curriculares Nacionais dos cursos de graduação em Direito, Ciências Econômicas, Administração, Ciências Contábeis, Turismo, Hotelaria, Secretariado Executivo, Música, Dança, Teatro e Design. Brasília: Diário Oficial da União. 2002. Disponível em: <http://portal.mec.gov.br/sesu/arquivos/pdf/14602DCEACTHSEMDTD.pdf>. Acesso em 23 out. 2017.

COLOMBO, Irineu Mario; BALLÃO, Carmen Mazepa. Histórico e aplicação da legislação de estágio no Brasil. Educar em Revista. Curitiba, n. 53, p. 171-186, jul./set. 2014. Disponível em: $<$ http://www.scielo.br/scielo.php?script=sci_arttext\&pid=S0104-40602014000300011\&lang=pt>. Acesso em: 09 abr. 2017.

FESTINALLI, Rosane Calgaro; CANOPF, Liliane; BERTUOL, Ornella. Estágio supervisionado em administração: reflexos de sua contribuição para a formação profissional. Revista Faz Ciência, v. 9, n. 9, p. 299-322, 2007. Disponível em: < http://e-revista.unioeste.br/index.php/fazciencia/article/view/7510>. Acesso em: 23 abr. 2017.

MINTZBERG, Henry; GOSLING, Jonathan. Educando administradores além das fronteiras. RAE-Revista de Administração de Empresas. Vol. 43, n. 2, p. 29-43, abr.jun. 2003. Disponível em: <http://rae.fgv.br/rae/vol43num2-2003/educando-administradores-alem-fronteiras.>. Acesso em: 24 set. 2017. 
MURARI, Juliana de Melo Franco; HELAL, Diogo Henrique. O estágio e a formação de competências profissionais em estudantes de administração. Revista Gestão e Planejamento. Salvador, v. 10 n. 2, p. 262-280, jul./dez. 2009. Disponível em: < http://www.revistas.unifacs.br/index.php/rgb/article/view/787> . Acesso em: 23 abr. 2017.

NICOLINI, Alexandre. Qual será o futuro das fábricas de Administradores?. RAE-Revista de Administração de Empresas, [S.I.], V. 43, n. 2, p. 44-54, abr.-jun. 2003. Disponível em: < http://rae.fgv.br/rae/vol43-num2-2003/qualsera-futuro-fabricas-administradores>. Acesso em: 01 out. 2017.

PICONEZ, Stela C. Bertholo (coord.). A prática de ensino e o estágio supervisionado. 24 ed. Campinas: Papirus, 2012.

ROCHA-DE-OLIVEIRA, Sidinei; PICCININI, Valmiria. A construção do mercado de estágios em administração na cidade de porto alegre. Revista pensamento contemporâneo em administração. Rio de Janeiro, v. 6, n. 4, p. 2948, out./dez. 2012. Disponível em: < http://www.uff.br/var/www/htdocs/pae/index.php/pca/article/view/246>. Acesso em: 23 abr. 2017.

ROESCH, Sylvia Maria Azevedo. Projetos de estágio e de pesquisa em administração: guia para estágios, trabalhos de conclusão, dissertações e estudo de caso. 3. ed. São Paulo: Atlas, 2009.

SOUZA. Vera Lúcia Pereira de; AMORIM. Tania Nobre Gonçalves Ferreira; SILVA. Ladjane de Barros. O estágio: ferramenta fundamental para a inserção no mercado de trabalho?. RACE, Unoesc, v. 10, n. 2, p. 269-294, jul./dez. 2011. Disponível em: <editora.unoesc.edu.br/index.php/race/article/view/1725>. Acesso em: 20 de ago de 2017. 